\title{
DEFINING COOPERATIVE BUSINESS MODELS FOR INTERORGANIZATIONAL COOPERATION
}

\author{
Alessio Maria Braccini \\ University of Tuscia \\ Via del Paradiso 47, 01100 Viterbo, Italy \\ abraccini@unitus.it \\ Paolo Spagnoletti \\ LUISS Guido Carli University \\ Via G. Alberoni 7, 00198 Rome, Italy \\ pspagnoletti@luiss.it \\ Alessandro D'Atri \\ LUISS Guido Carli University \\ Via G. Alberoni 7, 00198 Rome, Italy \\ datri@luiss.it
}

\begin{abstract}
Usage of software platforms alongside the business transformation potential of information and communication technology enables cooperation between different companies in both open and networked environments. This is possible when multiple actors cooperate in the delivery of services; each one contributes its own resources, and there is an underlying attractive business model for all of the players involved. This research paper investigates the definition process of a cooperative business model, which involves partners from different countries with different levels of technology, different markets, and different statutory regulations. The aim of this paper is to contribute to both theory and practice by introducing an approach for a cooperative business model definition that can be used in instances where there are conflicting requirements of partners who are willing to cooperate. In the case which is analyzed in this paper, the premature identification of the exploitation alternative scenarios among partners, the adoption of a perspective based on customers' needs by the means of the business episode concept, and the usage of the business model ontology for the description of the structure of the cooperative business model, have helped the different partners to successfully converge to a common and agreed solution.
\end{abstract}


Keywords: Cooperative Business Model, Business Episode, IT Exploitation, Cooperative Technologies, Action Research

\section{INTRODUCTION}

Information Technology (IT) solutions can be potential enablers for operational excellence, efficiency, and business transformation ${ }^{1}$. In a recent essay, Hanseth and Lyytinen ${ }^{2}$ defined a classification of IT solutions whereby IT capabilities, applications, platforms, and information infrastructures represent classes of increasing complexity. Their analysis of platforms that embed both IT capabilities and applications, poses the basis for the development of information infrastructures and the mechanisms to deal with a heterogeneous and growing user base.

These platforms enable large monolithic organizations which cover a broad range of services, distribution channels, and customer segments to transform into networked organizations that are focused either on a specific production process or on a specific customer process in cooperation with other organizations ${ }^{3}$. Such a scenario raises the importance of concentrating on the issue of developing new services. According to the open innovation approach, this is possible in an open networked environment in which multiple actors (both public and private) collaborate on delivering innovative services with an underlying business model that is attractive to all participants involved ${ }^{4}$.

Service innovations and business models do not belong exclusively to the private sector domain, but are also a concern for the public sector through the actions of e-government ${ }^{5}$. Indeed, the European Union (EU) defines e-government as the deployment of ICT in public administration combined with organizational change and new skills in order to improve public services and democratic processes, as well as the strengthening of support to public policies ${ }^{6}$. The European strategy on e-government aims to bring public administration closer to citizens and enterprises through the provision of innovative services by facilitating the interoperability of services and systems among public administration, as well as between administration and the public (citizens and enterprises) at a pan-European level ${ }^{7}$. In order to translate this objective into practice, a series of recommendations have been issued as a practical guide for reaching organizational interoperability among service providers. Within the guidelines, concepts such as a One-stop shop approach, Life event, and Business Episode are defined in order to facilitate implementation of new services ${ }^{7}$. 
The objective of this paper is to investigate the definition process of a cooperative business model for an innovative platform used to deliver e-government services within the context of the EU. This paper aims to contribute to the literature in two ways. First, from a practical point of view we describe a method for the definition of a cooperative business model for a cross-border e-service platform that has been used in a real case scenario. Second, from a theoretical point of view, we generalize the conclusions drawn from the application of the proposed method. This paper is based on the results of an empirical study performed in the setting of a European project, using an action research approach.

The paper is structured as follows: our conceptual model is introduced after a literature review in section 2. Section 3 illustrates in detail the research question and the methodology used. The case will be described in section 4, and discussed in section 5. Some final remarks on limitations and contributions in section 6 will conclude the paper.

\section{BACKGROUND LITERATURE}

ICT, among global competition, unstable markets, the blurring of industrial and organizational boundaries, is one of the factors that has contributed to changing the way organizations generate value ${ }^{8,9,10}$. ICT impacts traditional methods of doing business by continuously offering new opportunities ${ }^{11}$. Due to the possibility of reconfiguring tasks, roles, and relationships among actors involved in the value generation process ${ }^{8}$, traditional value chains are deconstructed and reconstructed to form new combinations that offer greater opportunities for the creation of new value ${ }^{12 \text {, }}$ ${ }^{13}$. In such a scenario, the theoretical concept of a business model has been used to describe these new opportunities ${ }^{5,14,15}$.

Literature on business models is an ever-growing corpus of research that receives contributions from a wide range of disciplines including management, strategy, e-business, and information systems ${ }^{11,16,17}$. The concept of a business model (or its variant forms such as e-business models, web business models, or internet business models) is of interest for different stakeholders such as investors, practitioners, entrepreneurs, and academics ${ }^{17}$, 18,19 , sometimes being utilized ambiguously ${ }^{20,21}$.

Due to the presence of multiple perspectives and the relative novelty of the concept, there are naturally different descriptions ${ }^{11,16,22,23,24,25}$. For example, Shafer et al. ${ }^{17}$ report 12 different definitions of the term business model in established publications during the period 1998 to 2002. A more complete list of several definitions of business model available can be found described in Braccini ${ }^{26}$. 
The core of the business model concept is its capability to describe how value is generated ${ }^{13,18,23,27,28,29,30,31}$. The business model then clearly communicates the business logic underlying the value generating process ${ }^{17}$, $19,24,32$

\subsection{Cooperative Business Models}

In a context where the boundaries of organizations are becoming increasingly blurred, value creation happens more and more thanks to a set of organizations that work together in networks ${ }^{8}$, developing strategic relationships that range from loose outsourcing to seamless integration ${ }^{33}$. These relationships are durable and sustainable only when all parties have incentives to partake and equitably share the value produced ${ }^{33}$.

Applying the business model concept in such scenarios means describing the inter-organizational activities and roles that enable value generation $^{30}$. In such cooperative scenarios, different requirements, which are sometimes conflicting, have to be balanced among players to achieve the sustainability and attractiveness of the business mode ${ }^{34}$.

\subsection{Applying the Business Model in Practice}

The heterogeneity of contributions regarding the business model concept presents challenges when applied to practical environments. Pateli and Giaglis ${ }^{11}$ have identified in the literature the following frameworks to apply the business model concept to practical situations: the $\mathrm{e}^{3}$ value ontology by Gordijn and Akkermans ${ }^{35}$; the Business Model Ontology (BMO) by Osterwalder and Pigneur ${ }^{30}$; and, the two conceptual models proposed by Winter $^{36}$, and Hedman and Kalling ${ }^{16}$.

Winter ${ }^{36}$ proposes a conceptual model and a formalism to describe and model a business strategy. This model focuses on companies of a specific industry playing the 'service integrator' role $^{36}$. Hedman and Kalling ${ }^{16}$ instead propose a business model that is useful to explain the relationship between IS and strategy, and has been tested with an ERP implementation in a European multi-national company. Gordijn and Akkermans ${ }^{35}$, and Osterwalder and Pigneur ${ }^{30}$ propose instead two different ontologies (the $\mathrm{e}^{3}$ value, and the BMO, respectively) to apply the business model concept in every context regardless of company type (e.g. industrial company or service provider). For the needs of the activities described in this paper, the BMO has been chosen as a conceptual tool for the business model definition.

\subsection{The Business Model Ontology}

The BMO was first introduced by Osterwalder and Pigneur ${ }^{30}$, and later discussed by Osterwalder et al. ${ }^{24}$. It describes the meta-model of a generic 
business model as a set of classes and their relationships. Semantics is provided for all of these elements and is used to describe, in an unambiguous way, what these classes and relationships are intended to represent. According to the BMO, a business model is a "conceptual tool that contains a set of elements and their relationships and allows expressing a company's logic of earning money. It is a description of the value a company offers to one or several segments of customers and the architecture of the firm and its network of partners for creating, marketing and delivering this value and relationship capital, in order to generate profitable and sustainable revenue streams"24.

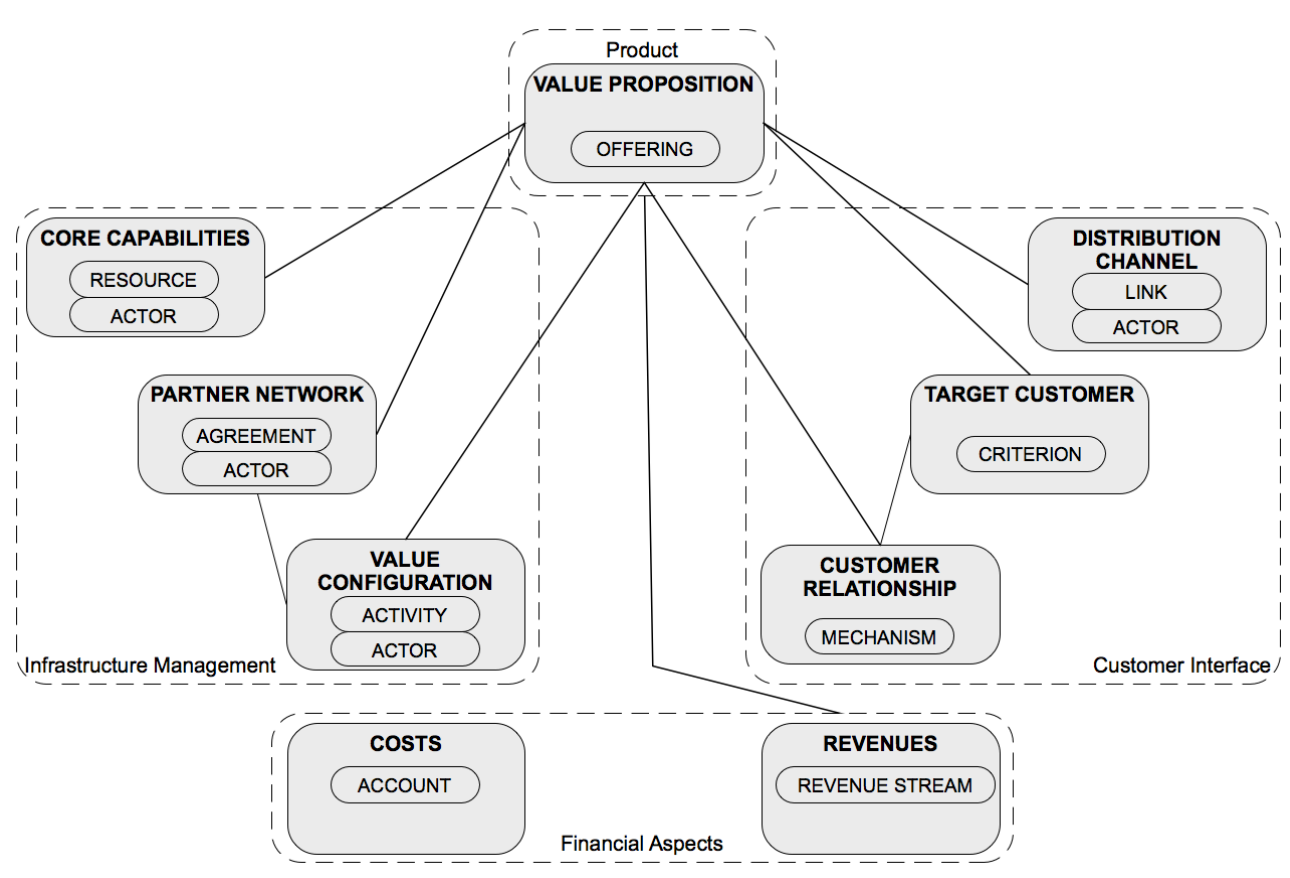

Figure 1. The structure of the BMO

The BMO adopts the perspective of a single organization and describes the structure of a business model as being composed of four pillars: product, infrastructure management, customer interface, and financial aspects. Each area contains a set of elements described according to various classes. The resulting structure is depicted in Figure 1.

The product area gives an overview of the products and/or services offered by a company to its customers. In this area, the value proposition represents, as a bundle, the value delivered to one or more customers. Each value proposition can be broken down into one or more offerings that are then presented to the customer. The customer interface describes the exterior aspects of the business model that put the firm in contact with the 
customer and the market. The offerings are presented to one or more target customer(s). Customers are usually classified together in groups according to a specific set of criteria (reported as criterion in Figure 1). Each target customer is approached by means of one (or more) distribution channel $(s)$. The distribution channel identifies, in an aggregated way, how the company reaches the customers. Each distribution channel can be broken down into a set of links, and one (or more) actor(s) can operate these links. The company manages a specific customer relationship strategy formed by one (or more) mechanism(s) through which contact with the customer is achieved and maintained.

The infrastructure management area describes the internal structure of the company that is pertinent to the execution of the business model. Each offering is delivered to the customer due to the activities and actors, composing a value configuration that contributes to deliver value. Part of these activities can be executed in-house or outsourced to a partner network based on an agreement that can be executed by an actor. To deliver the value proposition, the company has to possess specific capabilities in the form of the ability to execute repetitive patterns of actions and to control various resources (tangible, intangible, and human assets). Finally, the financial aspects of the business model identify the necessary balance between costs accounts and revenue streams.

\section{RESEARCH DESIGN}

This paper focuses on the process of the definition of a cooperative business model in a cross-border scenario. The unit of analysis is composed by all project activities (e.g. meetings, discussions, and definition of deliverables etc.) and all actions performed by members of the project consortium during the exploitation phase of the LD-CAST (Local Development Cooperation Actions enabled by Semantic Technology) European project funded under the $6^{\text {th }}$ Framework Programme.

The LD-CAST project aimed to foster cross-border cooperation between European chambers of commerce to support the development of private company initiatives by means of a platform that makes use of semantic technologies. The project consortium was formed by two research centers on information systems (from Italy and Greece), representatives from the Chambers of Commerce of four European member states (Bulgaria, Italy, Poland, and Romania), and three system integrators (from Italy, Austria, and Romania).

This paper is focused on answering the following research question that emerged as an issue for the successful completion of the LD-CAST project: 
Q: How is it possible to define a cooperative business model for a platform used by organizations providing services in different countries, with different technological levels, different markets, and different statutory regulations?

A participatory action research approach has been adopted as the methodology to investigate this question. This approach was adopted as it was very close to the ideology of the LD-CAST project where: (a) the researchers are actively involved; (b) benefits are expected both for the researchers and for the companies doing business; (c) the knowledge obtained during the research can immediately be applied; and, (c) the research process links theory and practice ${ }^{37,38,39}$.

In order to achieve scientific rigor, an additional structure is usually imposed upon action research projects ${ }^{39}$. The five steps proposed by Susman and Everred ${ }^{40}$, and identified as the most effective approach for action research $^{39}, 41,42,43$ were also used to enhance rigor. These five steps (diagnosis, action planning, action taking, evaluation, and learning) are either carried out in a sequential (like in our case), or in a iterated way. In this case, due to the strict sequence of project activities, no iterations were made. The sequence of these five phases are used as a structure to describe the case in the next section, to provide better description of the activities that were performed during each phase.

The case description and discussion focuses on the data collected during the project activities. Data for the description and the discussion of the case have been collected both from official project documents (deliverables, minutes of meetings) and from personal notes and direct experience of the authors. Two of the authors of this paper were involved in the project activities from the very beginning. The third author entered the project during the final phase.

\section{CASE DESCRIPTION}

The objective of the LD-CAST project was to build a European network of LD-CAST portals enabling end users (mainly private companies) to seamlessly access the services provided by organizations registered in each LD-CAST portal (mainly by chambers of commerce) in a cross-border scenario. All of these portals were required to run the LD-CAST software platform developed by the same project. The network was accompanied by a coherent set of guidelines for realizing and harnessing one-stop shop model platforms on all levels (European, national, regional and local) compliant with the European Interoperability Framework (EIF) guidelines without requiring changes to working procedures and systems of the participating organizations. In order to facilitate the interoperability between the different 
chambers of commerce acting as service providers, a common ontology was defined to model processes, services and different types of user requests.

During the 30-month life cycle of the project, the consortium developed a prototype to demonstrate how the LD-CAST platform can support cross-border cooperative service delivery. During the project, research institutes actively contributed towards defining the ontologies and process modeling. Furthermore, chambers of commerce supported the definition of the processes and services addressed. Technological activities required for the implementation and operations of the prototype were performed in Austria, Italy and Romania. An integrated field test was carried out in Bulgaria, Italy, Poland, and Romania.

The LD-CAST cooperative platform was designed to provide new services to small medium enterprises (SMEs). Typical SMEs are too small to have all necessary internal procedural and legal competences required to expand their business internationally, and have to rely on services provided by professionals or chambers of commerce. In a cross-border scenario, due to the fundamental differences of language and regulation that exists among countries, it might be difficult for an SME to know exactly which services the foreign chamber of commerce provides to support establishing a partnership with a foreign company. The LD-CAST platform aims to support the service delivery of the chambers of commerce to the SMEs in such situations using semantic technologies.

\subsection{Diagnosis: How to Define a Cooperative Business Model for LD-CAST}

The definition of a detailed exploitation plan was requested by the EU Commission in order to complete the project. A total of 49 man/months were allocated to the "Dissemination and Exploitation" work package (13\% of the overall effort). The definition of a cooperative business model for the LD-CAST platform was a key element and one of the components required for the "Dissemination and Exploitation Plan" project deliverable. The first version of this was delivered six months after the project started. In this version, each project partner clearly identified its own commercial exploitation strategy with regard to the exploitable results of the project. These strategies were regularly updated every six months according to the project findings, and changes in the market.

In the definition of the LD-CAST business model, the differences across partners and their strategies posed many challenges. One of the major exploitable results was setting up the LD-CAST "one-stop shop" agencies: single points of contact to sell services to service providers. Other exploitable results were the provision of the LD-CAST software platform to 
organizations willing to interconnect e-services from different public authorities into a single portal, and alternatively, the provision of consultancy services to support organizations willing to integrate the LD-CAST platform in their individual/proprietary platforms.

The organizations involved in the project consortium showed remarkable differences regarding their exploitation potential and capabilities. At first, the technological partners were more interested in providing/selling LD-CAST software products to the maximum number of customers. Chambers of commerce were more interested in exploiting the new business services developed through the LD-CAST platform to support their daily service delivery to customers; however, constraints were imposed by different statutory regulations. In Italy, the chambers of commerce are essentially public administration whose main goal is both supporting Italian entrepreneurs to expand their business, as well as reducing internal costs. These institutions have no interest in increasing their customer base, since organizations are required to register with the chambers of commerce. In contrast, the chambers of commerce in the other three countries are private organizations and act following a pure business approach. Finally, universities and scientific partners were not directly interested in the daily service provisioning activity made possible by the LD-CAST platform, but were mainly interested in providing services for the maintenance of the LD-CAST glossary and semantic content.

Since the beginning of the project, the LD-CAST business model was intended to build upon the concept of a central agency, the "virtual" point-of-sale of LD-CAST services, which had corresponded to an interoperable one-stop shop business portal accessible (directly or indirectly through the chambers of commerce) by the end users (small and medium enterprises). Such a portal would have used the LD-CAST platform to sell automated or semi-automated services to SMEs through the chambers of commerce providing those services. In this context, the partners decided to create a legal entity for the licensing and the exploitation of the core and transferable elements from the project. Centralizing content-related investment is considered to be vital in fostering the service deployment beyond the project duration; none of the partners were able to do this on their own. Cooperation with third parties was also required e.g. with initiatives, such as agreements with the European business register.

The different interests, constraints and conflicting requirements described in this section need to be seen in the context of the definition of a cooperative business model for such a legal entity. Moreover, a common understanding of the business model concept was necessary among all of the partners, since each one was focusing only on partial aspects of the entire 
business model. Project partners then devised a more appropriate and effective method that could support the definition of such a business model, even with the inherent constraints of the model implementation process. Italian representatives of the chambers of commerce and the researchers were the main partners responsible for providing and discussing such a method.

\subsection{Action Planning}

The adoption of the BMO and the concept of the business episode for the definition of the cooperative business model for the LD-CAST platform was proposed and eventually accepted by the entire project consortium. The BMO was chosen in favor of another alternative approach, the $\mathrm{e}^{3}$ value ontology. The two approaches were discussed at great length in two internal meetings, and the BMO was chosen for two reasons. First, the hierarchical structure of the BMO allows the investigation of the business model in a top-down perspective. Second, project partners found the jargon of the $\mathrm{BMO}$ easier to understand. The BMO describes a business model in terms of its products, customers, infrastructures and financial aspects, elements that each partner could use in daily business life. The BMO was deemed a useful tool for the partners to share the same definition and structure of the business model concept. For the definition of the LD-CAST cooperative business model, since all partners had intended to play a role, their cooperation was necessary to clarify their contribution to the value proposition, the target customers, the infrastructure, and the financial aspects of the business model for the LD-CAST platform.

The core of the business model according to the BMO is the value proposition that describes the services (in the case of the LD-CAST platform) that are delivered to customers. Since the LD-CAST platform engages with different chambers of commerce upon users' requests to provide different services, the identification of services and groups of customers suitable for all emerged quickly as an issue. The business episode concept was useful to address such an issue, and was devised to achieve a shared understanding of the value proposition by the entire project consortium.

On the basis of the one-stop shop approach, services that can be delivered by the LD-CAST platform were grouped into business episodes. According to the information provided by the European Commission ${ }^{7}$, project partners defined a business episode as a self-standing event in the life of a business organization that corresponds to a specific need. In order to meet this need, chambers of commerce were called upon to deliver more than one service. In the respective participating member-states, these services differed in each member-state chambers of commerce. To deliver 
such services each chamber of commerce was required to execute different business processes.

In order to clarify this point, the following example can be used: a Polish company (client) wants to buy an elevator to be assembled locally. A Romanian company (supplier) will supply the cables, an Italian company (supplier) the engine, and a Bulgarian company (supplier) provides the cabin. The self-standing event (the business episode) in the life of the Polish company is to establish commercial relationships with foreign suppliers in order to construct the elevator. This business episode relates directly to the completion of the following steps (that were carried out for each supplier):

1) Legal cross-verifications: each company needs to cross-verify their legal and financial requirements, such as the purchase of an enterprise's certificate of existence, or a criminal report to establish whether the company has been involved in criminal acts in the past;

2) Fiscal cross-verifications: among the financial verifications, the enterprises may request cross-verifications on annual turnover or balance sheets to know if the companies are financially solvent and stable;

3) Technical \& quality standard requirements cross-verification: companies may request details on product certifications, certificates of conformity, or CE marking, ISO certificates, and similar;

4) General requirements: given the cross-border scenario, different regulations for different markets have to be expected. Assistance is then required to set prices, and to acquire sample contracts and so forth;

5) Agreements: if all these verifications are achieved the agreement can be finalized.

In each of these steps, the chambers of commerce can assist the companies with one or more specific services. Due to the differences in technological levels among the partners of the project, these services could be fully automated e-services, or human-based manual activities. The services/activities required to complete the business episode are different for every member state. As an example, Figure 2 shows how the different chambers of commerce (in Bulgaria, Italy, Poland, and Romania) respond to a legal verification request (step n. 1 in the previously described business episode). 

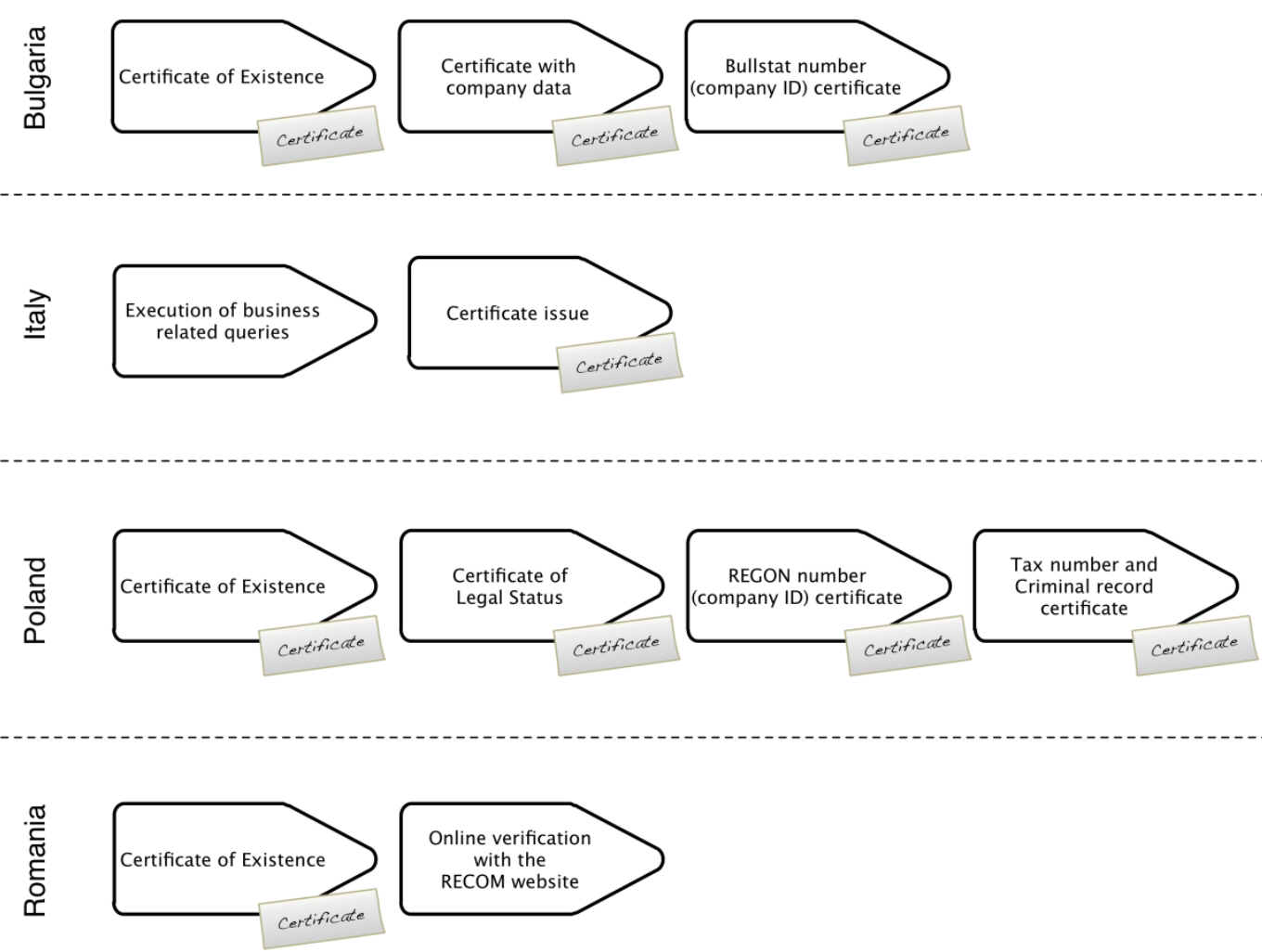

Figure 2. Services provided by the chambers of commerce for the purpose of legal verifications

\subsection{Action Taking}

The business episodes relevant for the LD-CAST scenario were defined during each phase of the project to identify the services that the chambers of commerce could offer through the LD-CAST platform, and the activities they had to execute in order to deliver. After that point, it became easier for the chambers of commerce to identify all other aspects related to the business model, such as customer interface, infrastructure management, and financial aspects. To investigate these aspects, the project consortium decided to circulate a questionnaire among all of the representatives from the chambers of commerce.

The resulting business model of the LD-CAST platform then embeds its value proposition in 12 business episodes as identified by project partners following a preliminary market analysis. These business episodes are targeted to different groups of customers in each country: students and businesses in Italy, business consultants in Poland and Bulgaria, and professional associations in Romania. The services used to complete the 
business episodes are offered through a variety of distribution channels, the principal of which is LD-CAST platform itself.

With regard to the value configuration that provides the service delivery, services can be delivered to customers either by automatic e-services or by human-based activities (such as in countries where, due to the current level of technological development, e-services are not so widely used among service providers). The LD-CAST platform creates the possibility to provide this mixture of automated and manual service delivery. In order to deliver such services, strategic partners were identified in all four countries: 10 local chambers of commerce in Bulgaria, 6 Italian chambers of commerce and special agencies for foreign affairs, and 8 local chambers of commerce each in Poland and Romania.

From a financial perspective, partners identified royalties to be a major source of revenue. These royalties were expected to come from the installation of the LD-CAST system to service providers (actual and new ones) and from the sales of services to identified customers. The main costs necessary to sustain the LD-CAST business model was related to the cost of sales, the development and the maintenance of the software platform, and of the technological infrastructure. Costs and revenues were forecasted over a five-year period following a traditional business plan approach.

\subsection{Evaluation}

The evaluation process has seen two main steps. The first step involved the evaluation of the suitability of the LD-CAST platform by all project partners in agreement. The business model was inserted into the "Dissemination and Exploitation Plan" project deliverable issued at the end of the project, which included a section describing both the exploitation process and its results. In a second step, experts and reviewers from the European Commission also validated and approved the dissemination and exploitation plan (in which the business model was included), at the end of the project's lifecycle.

\section{CASE STUDY DISCUSSION: LESSONS LEARNED FROM THE LD-CAST COOPERATIVE BUSINESS MODEL CASE}

This paragraph summarizes the learning phase of our action research activity. To answer our research question, the BMO complemented the business episode concept and formed suitable instruments to successfully define a cooperative business model that involves different organizations acting in different countries with varying technological levels, as well as disparate statutory regulations. The approach used to define the cooperative 
business model for LD-CAST was divided into three steps:

1. The identification of the exploitation alternative scenarios from all of the project partners from the very start of the project;

2. The adoption of an end user's perspective to identify the services, groups of customers and activities underlying the cooperation among partners (especially among service providers); and,

3. The deployment of the BMO to identify such requirements as the value proposition, customer interface, infrastructure management, and the costs and revenues of the cooperative business model.

The BMO helped in disseminating among the LD-CAST partners the same concepts and structures necessary for the definition of the cooperative business model. At the beginning of the project, two problems could be identified referring to the definition of the business model: the different understanding of the business model concept, and the presence of different exploitation strategies among the members of the project consortium. Both of these could have the potential to lead the process of the cooperative business model definition to a failure.

Regarding the first potential problem, the BMO permitted a member of the project consortium to go beyond the word "business model", and to agree on what should be discussed in order to define the business model for the platform. Although the BMO is just one framework that can support the definition of a business model, the closeness of its jargon to daily business life made it easier to be used in this particular context.

Concerning the second potential problem, since the BMO usually refers to a single organization and its value-generating process, there was the need to move each partner from a single perspective to the cooperative perspective. To do so, the concept of business episode complemented the BMO used in the cooperative environment.

\subsection{Implications for Theory}

Generalizing the experience of the LD-CAST project, to balance the different and conflicting requirements of partners in a cooperative business model, the business episode perspective was useful. Summarizing the set of tasks and services the service providers execute or deliver to fulfil the needs of end-users, the business episode forced all of them to think of the business model definition from a customer-centric perspective. Despite the presence of the software platform, the cooperation of all the partners in the LD-CAST project was cemented on the basis of the common users' needs that they wished to satisfy. This was made possible because of the heterogeneous nature of the customers and their needs involved in our case. 
In this respect, the business episode concept acted as an interface between the external users' needs and the internal requirements of the business model (Figure 3). On one hand, the business episode captured the end users' needs in a way that can be immediately tracked back to daily business activities. On the other hand, the business episode showed activities and services required by a company to satisfy such needs. According to the context established during the LD-CAST project, the business episode helped service providers identify how their services could find competitive space in a cooperative business model scenario.

A further point worth discussing was the relationship between the business episode and the other components of the BMO. On this point we can argue that the business episode was in relation to the three concepts of the BMO: the value proposition, target customer, and the value configuration. The point of contact with the value proposition was quite straightforward; the business episodes served to identify the activities and services used to satisfy the end users' needs that were indicated by the business episode itself. Moreover, since the business episode was a self-standing event in the life of a company, the business episode can also help identify the target customer. Finally, because the business episode was also connected to the activities are necessary to deliver the services to the customers, it helps to identify the activities necessary to deliver the value proposition to the customers.

A final comment regarding the business episode concept relates to the granularity with which it is applied. A specific business episode can be a part of a larger business episode. Referring to the example given in the action-planning paragraph, the legal cross-verification formed part of the business episode of an established commercial relationship with a foreign supplier. However, according to a company's need, a legal cross-verification can be a self-standing life event, and therefore a business episode in itself. This enables the definition of business episodes in an incremental way, starting from simple ones, and moving towards more complex.

The relationships of the business episode with the BMO are shown in Figure 3. 


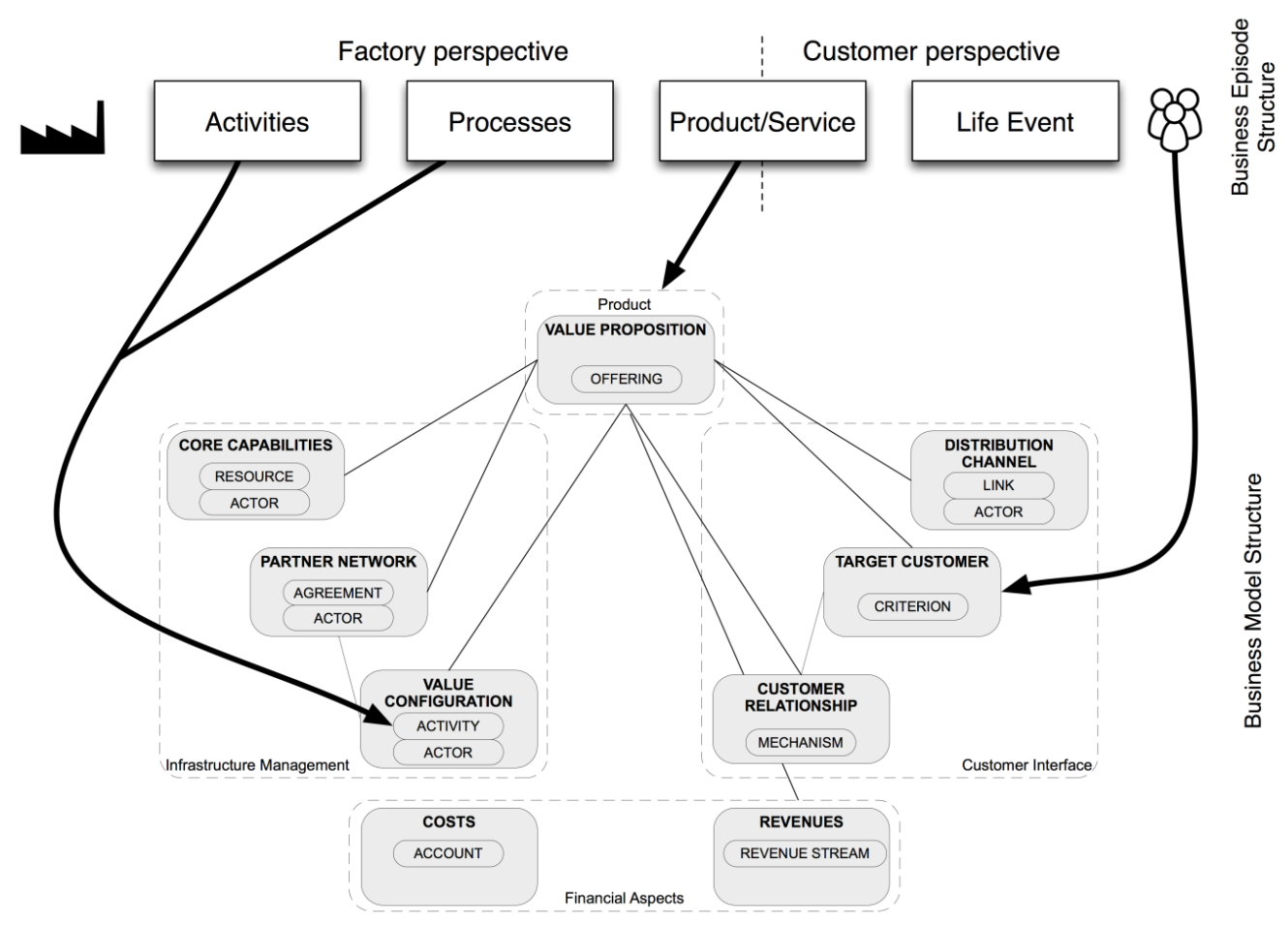

Figure 3. Relationships between the business episode and the business model

\subsection{Implications for Practice}

Increasingly, platforms like LD-CAST are designed and implemented inside project initiatives, even when they fall outside of the umbrella of European funding. Project consortia find themselves more often in conditions similar to those of the LD-CAST project. In the situations where a cooperative business model needs to be defined for a software platform, the approach described in this paper can be iterated. According to our experience, the premature identification of exploitation of alternative scenarios, the adoption of customers' needs in a centric perspective, and the use of the BMO, are suitable means for allowing project partners to achieve a common solution. In particular, the business episode concept helped partners to identify how they can cooperate by addressing common users' needs, guiding them towards harnessing the core components of the business model, specifically the value proposition. Since the business episode includes three components (the self-standing event, the customer, and the services/activities performed by the service providers), it is also a gateway to discuss the customer interface, the infrastructure management, and the costs and revenue of the cooperative business model. Moreover, in the presence of different exploitation alternative scenarios, the approach can 
help to converge to one solution.

\section{CONCLUSIONS}

This paper describes the definition process of a cooperative business model for the provision and delivery of services through a software platform. The empirical research was based on the LD-CAST European project. In highlighting the difficulties that the project partners encountered in order to address different and conflicting exploitation scenarios and business requirements, this paper has shown that a customer-centric approach for defining a cooperative business model, making use of the business episode concept and BMO, is indeed a suitable approach. Even though this approach has been successfully adopted in a large European project with several different partners, we would like to discuss some possible limitations of our findings.

First, a minor limitation resides in our inability to provide proof of the effectiveness of the LD-CAST business model, since project partners have not yet started their business activities. However we believe that this limitation is minor since we are targeting the process of the definition of the cooperative business model. A second limitation concerns the methodology applied during the analysis of the case. Due to the sequential nature of the LD-CAST project activities, there have been no iterations of action research steps (as possible in a canonical action research process).

Finally, regarding the practical application of the approach proposed herein, we believe two further limitations should be discussed. The first concerns the differences in terms of language, technological level, and regulations of the partners. Even though in the case description we have discussed these differences, it has to be noted that all partners involved in the project were (at the time) either full or candidate members of the European Union. The differences among these partners could then be lower than those possibly existing between partners of a developed and an under-developed country. The second issue regards the successful completion of the cooperative business model development process. In the case of the LD-CAST project, this was part of the project activities. The successful completion of the project activities was a necessary condition to obtain grants from the European Commission. This circumstance could have constituted an incentive to all project partners to commit to the success of their activities. We believe that the possible influence of this incentive on the application of the method proposed is worthy of further attention. 


\section{REFERENCES}

[1] N. Venkatraman, IT-enabled business transformation: from automation to business scope redefinition. Sloan Management Review, 35(2), p73-87, 1994.

[2] O. Hanseth, and K. Lyytinen, Design theory for dynamic complexity in information infrastructures: The case of building Internet. Journal of Information Technology, 25(1), p1-19, 2010. doi:10.1057/jit.2009.19.

[3] P. Weill, and M.R. Vitale, Place to space: Migrating to e-business models. Boston: Harvard Business School Press, 2001.

[4] H.W. Chesbrough, Open innovation: The new imperative for creating and profiting from technology. Boston: Harvard Business School Press, 2003.

[5] M. Janssen, G. Kuk, and R.W. Wagennar, A survey of web-based business models for e-government in the Netherlands. Government Information Quarterly, 25(2), p202-220, 2008. doi:10.1016/j.giq.2007.06.005.

[6] European Commission, The role of government for Europe's future, eGovernment communication. Retrieved on March 30, 2011, from http://ec.europa.eu/information_society/eeurope/2005/doc/all_about/eg ov_communication_en.pdf.

[7] European Commission, European interoperability framework for Pan-European e-Government services. Retrieved on March 30, 2011, from http://ec.europa.eu/idabc/servlets/Doca2cd.pdf?id=19528.

[8] R. Normann, and R. Ramirez, From value chain to value constellation: Designing interactive strategy. Harvard Business Review, 71(4), p65-77, 1993.

[9] C.B. Stabel, and Ø.D. Fjeldstad, Configuring value for competitive advantage: On chains, shops and networks. Strategic Management Journal, 19, p413-437, 1998. doi:10.1002/(SICI)1097-0266(199805)19:5<413::AID-SMJ946>3.3.C O;2-3.

[10] O.A.E. Sawy, A. Malhotra, S. Gosain, and K.M. Young, IT-intensive value innovation in the electronic economy: Insights from Marshall industries. MIS Quarterly, 23(3), p305-335, 1999. doi:10.2307/249466.

[11] A.G. Pateli, and G.M. Giaglis, A research framework for analysing eBusiness models. European Journal of Information Systems, 13(4), p302-314, 2004. doi:10.1057/palgrave.ejis.3000513.

[12] D. Straub, A. Rai, and R. Klein, Measuring firm performance at the network level: A nomology of the business impact of digital supply networks. Journal of Management Information Systems, 21(1), p83-114, 2004. 
[13] L. Schweizer, Concept and evolution of business models. Journal of General Management, 31(2), p37-56, 2005.

[14] HBR, The 2001 HBR List. Breakthrough ideas for today's business agenda. Harvard Business Review, 79(4), p123-128, 2001.

[15] P.W.G. Keen, and S. Qureshi, Organizational transformation through business models: A Framework for business model design. Paper presented at 39th Hawaii International Conference on Information Systems, Kauai, Hawaii, USA, January 4-7, 2006. doi:10.1109/HICSS.2006.376.

[16] J. Hedman, and T. Kalling, The business model concept: Theoretical underpinnings and empirical illustrations. European Journal of Information Systems, 12(1), p49-59, 2003. doi:10.1057/palgrave.ejis.3000446.

[17] S.M. Shafer, H.J. Smith, and J.C. Linder, The power of business models. Business Horizons, 48(3), p199-207, 2005. doi:10.1016/j.bushor.2004.10.014.

[18] H. Chesbrough, and R.S. Rosenbloom, The role of the business model in capturing value from innovation: Evidence from Xerox. Industrial and Corporate Change, 11(3), p529-555, 2002. doi:10.1093/icc/11.3.529.

[19] J. Magretta, Why business models matter. Harvard Business Review, 80(5), p86-92, 2002.

[20] R.C. Calia, F.M. Guerrini, and G.L. Moura, Innovation networks: From technological development to business model reconfiguration. Technovation, 27(8), p426-432, 2007. doi:10.1016/j.technovation.2006.08.003.

[21] L. Willemstein, T. van der Valk, and M.T.H. Meeus, Dynamics in business models: An empirical analysis of medical biotechnology firms in the Netherlands. Technovation, 27(4), p221-232, 2007. doi:10.1016/j.technovation.2006.08.005.

[22] P. Timmers, Business model for electronic markets. Electronic Markets, 8(2), p3-8, 1998. doi:10.1080/10196789800000016.

[23] B. Mahadevan, Business models for internet-based e-commerce: An anatomy. California Management Review, 42(4), p55-69, 2000. doi:10.2307/41166053.

[24] A. Osterwalder, Y. Pigneur, and C.L. Tucci, Clarifying business models: Origins, present, and future of the concept. Communications of the Association for Information Systems, 15, p1-25, 2005.

[25] H. Tikkanen, J.A. Lamberg, P. Parvinen, and J.P. Kallunki, Managerial cognition, action and the business model of the firm. Management Decision, 43(6), p789-809, 2005. doi:10.1108/00251740510603565.

[26] A.M. Braccini, Value Generation in Organisations. Saarbrücken, Germany: LAMBERT Academic Publishing, 2011. 
[27] R.E.S. Boulton, B.D. Libert, and S.M. Samek, A business model for the new economy. Journal of Business Strategy, 21(4), p29-35, 2000. doi:10.1108/eb040102.

[28] R.E. Miles, C.C. Snow, and G. Miles, The Future.org. Long Range Planning, 33(3), p300-321, 2000.

[29] M. Dubosson-Torbay, A. Osterwalder, and Y. Pigneur, eBusiness model design, classification and measurements. Thunderbird International Business Review, 44(1), p5-23, 2002.

[30] A. Osterwalder, and Y. Pigneur, An eBusiness model ontology for modeling eBusiness. Paper presented at 15th Bled Electronic Commerce Conference-eReality: Constructing the eEconomy, Bled, Slovenia, June 17-19, 2002.

[31] S. Voelpel, M. Leibold, E. Tekie, and G. von Krogh, Escaping the red queen effect in competitive strategy: Sense-testing business models. European Management Journal, 23(1), p37-49, 2005. doi:10.1016/j.emj.2004.12.008.

[32] J.D. Owens, A business model can make the Difference. Management Services, 50(1), p24-28, 2006.

[33] R. Kohli, and V. Grover, Business value of IT: An essay on expanding research directions to keep up with the times. Journal of the Association for Information Systems, 9(1), p23-39, 2008.

[34] M.M. Al-Debei, and D. Avison, Business model requirements and challenges in the mobile telecommunication sector. Journal of Organizational Transformation and Social Change, 8(2), p215, 2009. doi:10.1386/jots.8.2.215_1.

[35] J. Gordijn, and H. Akkermans, E3-value: Design and evaluation of e-business models. IEEE Intelligent Systems, 16(4), p11-17, 2001. doi:10.1109/5254.941353.

[36] R. Winter, Conceptual modeling of business networks and business strategies. Paper presented at 16th Bled eCommerce Conference eTransformation, Bled, Slovenia, June 9-11, 2003.

[37] R.N. Rapoport, Three dilemmas in action research. Human Relations, 23(6), p499-513, 1970. doi:10.1177/001872677002300601.

[38] R.L. Baskerville, and T.A. Wood-Harper, A critical perspective on action research as a method for information systems research. Journal of Information Technology, 11(3), p235-246, 1996. doi:10.1080/026839696345289.

[39] R.L. Baskerville, Investigating information systems with action research. Communications of the Association for Information Systems, 14(1), p28-45, 1999. 
[40] G.I. Susman, and R.D. Evered, An assessment of the scientific merits of action research. Administrative Science Quarterly, 23(4), p582-603, 1978. doi:10.2307/2392581.

[41] R.L. Baskerville, and J. Pries-Heje, Grounded action research: A method for understanding IT in practice. Accounting Management and Information Technology, 9(1), p1-23, 1999. doi:10.1016/S0959-8022(98)00017-4.

[42] D. DeLuca, M.J. Gallivan, and N. Kock, Furthering information systems action research: A post-positivist synthesis of four dialectics. Journal of the Association for Information Systems, 9(2), p48-72, 2008.

[43] R.M. Davison, M.G. Martinsons, and N. Knock, Principles of Canonical Action Research. Information Systems Journal, 14(1), p65-86, 2004. doi:10.1111/j.1365-2575.2004.00162.x. 
